\title{
Effect of Red-Fleshed Pitaya (Hylocereus Polyrhizus) to Increase Gluthatione Peroxidase Levels in Male Rats (Rattus Norvegicus): The Induced Oxidative Stress
}

\author{
Novita Sari Harahap ${ }^{1}$, Fajar Apollo Sinaga ${ }^{2}$, Rika Nailuvar ${ }^{3}$, Rina Amelia ${ }^{4}$ \\ \{novitahrp74@gmail.com ${ }^{1}$ \} \\ Department of Sports Sciences, Faculty of Sports Sciences, Universitas Negeri Medan, Medan, \\ Indonesia $^{1}$ \\ Department of Community Medicine/Public Health, Faculty of Medicine, \\ Universitas Sumatera Utara, Medan, North Sumatera, Indonesia ${ }^{2,3,4}$
}

\begin{abstract}
High intensity physical activity requires large amounts of antioxidants. Exhausting physical activity can decrease glutathione peroxides levels in response to increasing production of free radicals. Glutathione peroxides levels to eliminated free radicals and reduce oxidative damage. This study aims to know effect antioxidant redfleshed pitaya extract to increase glutathione peroxides. The subject of this research are 16 male rats, age 3 months with average weight of 200 gr, divided into 2 groups. Group 1 (OS-RFP) : the induced oxidative stress and given aquadest, group 2 (OS+RFP) : the induced oxidative stress and given $100 \mathrm{mg} / \mathrm{kgWB}$ of red-fleshed pitaya extract. Oxidative stress is given was swam for 20 minutes, thrice a week for 3 weeks. The glutathione peroxides levels in the group 1 higher than the group 2. There were significant differences in the increasing glutathione peroxides levels $(\mathrm{p}=0.000)$ between group 2 and group 1. This research shows that glutathione peroxides levels have increased in oxidative stress groups given red-fleshed pitaya extract. Red-fleshed pitaya extract has to increase glutathione peroxides levels that is can eliminate oxidative stress.
\end{abstract}

Keywords: Oxidative stress, glutathione peroxides, red-fleshed pitaya, rat..

\section{Introduction}

Exhausting physical exercise increases oxygen needs due to the increase of metabolism in the body. The rise of oxygen uptake is contracting muscle leads to ischemia reperfusion which causes one electron to detach from respiratory chain and forms free radicals (Power et al., 2008; , Sahlin et al., 2010).

In physiologist condition, the free radicals production will be balanced by the production of endogenous antioxidant in the body like glutathione peroxides (GPx). Glutathione peroxides is a natural antioxidant in the form of an enzyme, produces in the body, with a strong effect and as the first defense against attack from free radicals (Gomes et al., 2012).

The study done by Harahap et al. (2018) stated that a regular and controlled dosage of exercise, like weigh training, based on the ability of each individual can eliminate the free radicals and increase of glutathione peroxides levels, more over improve the performance of a 200-metre runner (Harahap et al., 2018).

Antioxidant activity depends on the intensity of exercise as exhausting physical exercise 
can decrease of glutathione peroxides levels in response against increasing of free radicals and to eliminated of free radicals and reduce oxidative damage.However, during high intensity physical activity, the free radicals production can be greater than gluthatione peroxides which results in oxidative stress (George and Osharechiren, 2009; El Abed et al., 2014).

Actually free radicals, including ROS (Reactive Oxygen Species), important for normal body healthy in reduce inflammation, phagocytosis and regulate the muscle tone of blood vessels and organs. However, if the balance of the free radicals and antioxidant is disturbs which results in oxidative stress (Valko et al., 2007; Cooper et al., 2002; Marciniak et al., 2009; Castrogiovanni, 2012). Oxidative stress cause heavy training has damages cells, muscles fatigues and decreases antioxidant levels (George and Osharechiren, 2009; Kurkcu et al., 2010; Azizbeigi et al., 2013).

To determine whether there is an increase in oxidative stress among others by analyzing the endogenous antioxidant content namely glutathione peroxides. The increased oxygen consumption during exercise will activate glutathione peroxides enzymes to move hydrogen peroxidase $\left(\mathrm{H}_{2} \mathrm{O}_{2}\right)$ from the cell. The affinity of glutathione peroxides against $\mathrm{H}_{2} \mathrm{O}_{2}$ is stronger than catalase. The location of glutathione peroxides is in mitochondria and cytosols to protect cells from free radicals that can damage lipid membranes, proteins and nucleic acids (Urso, 2013).

The body needs exogenous antioxidants to eliminate and prevent oxidative stress (Gomez et al., 2009). The sources of exogenous antioxidant are Vitamin $\mathrm{E}$ and $\mathrm{C}$ also beta-carotene. External antioxidant from food or supplement can to fight the excess of free radicals. Proanthocyanidin from grape seed was given to rats for 2 weeks. It lowers down Malondealdehyde levels, increases superoxide dismutase and glutathione peroxides activities significantly, moreover reduces fatigue after physical activities (Belviranli et al., 2006).

Red-fleshed pitaya (Hylocereus polyrhizus) is one type of fruits that is unique with a lot of benefits. The fruit is recently popular among the people in Indonesia and appears as natural antioxidant. Several invitro studies have shown that red-fleshed pitaya extract has the power as antioxidant (Sani et al., 2009; Nurul, 2014). This study aims to know effect antioxidant redfleshed pitaya extract to increase glutathione peroxides in male rats the induced oxidative stress.

\section{Methods}

\subsection{Animal}

The subject of this research are 16 male rats, age 3 months with average weight of 200 gram. Rats were acclimatized and maintained for 1 week to adapt in a groups of 4 rats per cage made of plastic material $(30 \times 20 \times 10 \mathrm{~cm})$ which is covered with fine wire mesh.

\subsection{Material and Reagents}

This study using red-fleshed pitaya extract obtained from methanol extraction process. Maceration technique was used and the extract was concentrated with air-drying method. Glutathione peroxidase levels were examined using ELISA method and spectrophotometry wavelength of $450 \mathrm{~nm}$ with mouse Glutathione peroxidase Elisa kit, catalog E1483Mo for glutathione peroxidase levels analysis. 


\subsection{Statistical Analysis}

Data were analyzed with statistics and presented in form of means and standard deviation, tables and figures. Each data obtained is first determined by the distribution of the Normality test.If the data is normally distributed, an independent $t$ test is performed.

\section{Results}

Table 1, the results of examination the glutathione peroxides levels are normally distributed. The mean glutathione peroxides level at the OS+RFP group was higher compared to the OS-RFP group $(32,24 \pm 2,43$ vs $24,69 \pm 4,69)$ (tabel 2$)$. This shows that glutathione peroxides levels an increase significant at the oxidative stress groups given red-fleshed pitaya compared to the oxidative stress group without given red-fleshed pitaya (figure 1).

Table 1. Normality test of the glutathione peroxides.

\begin{tabular}{lccc}
\hline \multirow{2}{*}{ Parameter } & Groups & statistic & $\mathrm{p}$ \\
\cline { 3 - 4 } & & 0.865 & $0.135^{*}$ \\
\hline $\begin{array}{l}\text { Glutathione } \\
\text { peroxides }\end{array}$ & OS-RFP & & \\
& OS+RFP & 0.895 & $0.263^{*}$ \\
\hline
\end{tabular}

Note: $*=$ signifikan $(\mathrm{p}>0,05), \mathrm{SD}:$ standard deviation

Table 2. Effect of Red-fleshed Pitaya to Increase Gluthatione Peroxidase levels.

\begin{tabular}{llll}
\hline Group & Mean & SD & p value \\
\hline OS-RFP & 24.69 & 4.69 & $0.000^{*}$ \\
OS+RFP & 32.24 & 2.43 & \\
\hline \multicolumn{4}{c}{ Note: ${ }^{*}=$ signifikan $(\mathrm{p}<0,05)$}
\end{tabular}

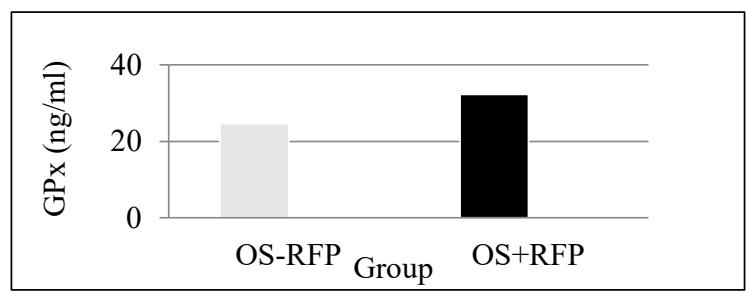

Fig. 1. Glutathione peroxides levels in OS-RFP group and OS+RFP group 


\section{Discussion}

The results of this study are found that exhausting physical exercise as a cause of oxidative stress when combined with giving red fleshed pitaya extract every day during exercise can increase glutathione peroxidase levels. Red fleshed pitaya extract with a dose of $100 \mathrm{mg} / \mathrm{kgBW}$ is better in increasing glutathione peroxidase levels.

The studyshowed that red fleshed pitaya extract has the potential as an exogenous antioxidant which can eliminate free radicals those formed during exhausting physical exercise are evidenced by increased gluthatione peroxidase levels.

Free radicals are compounds or atoms where the outer orbitals have unpaired electrons so that they are highly reactive to surrounding cells. Reactive compounds look for pairs, by attacking and binding to the molecular electrons around them and if these compounds meet new radicals, new radicals will form again and so on so that a chain reaction will occur (Kelsey and Bloomer, 2009).

Damage in biological molecules is affected by this oxidative stress (Finaud et al., 2006; Andersson et al., 2009; Kothari et al., 2010). Phosphorylation oxidation due to exhausting physical exercise is the main internal factor causing oxidative stress (Kurkcu et al., 2100).

Despite the effects of exercise on health benefits, many studies reported during exhausting physical exercise there is an ischemia-reperfusion process that causes the production of oxidative due to release it of electrons from the respiration chain. During exhausting physical exercise, the release of free radicals can increase in mitochondria and cause oxidative stress (Daniel et al., 2010; Escribano et al., 2010). Oxidative stress causes DNA damage, loss of protein structure function such as membrane enzymes and receptors, and structural damage from the lipid cell layer (Guzel et al., 2007; Abruzzo et al., 2013; Liu et al., 2013). The research by Norouziyan et al. in active women it has been found that Total Anti-Oxidant Capacity and Glutathione after exercise can be increase. This shows that exercise can be stimulating the body's ability to increase antioxidant (Norouziyan et al., 2014). Glutathione peroxides is an endogenous antioxidant that functions as free radicals catcher by releasing its own electrons to prevent oxidation from occurring and destroying other molecules. Glutathione peroxides is called as scavenger enzyme to hydrogen peroxide, found especially in mitochondria.

The high and low glutathione peroxides levels determine its activities as antioxidant. The higher of glutathione peroxides levels is, the higher the activities of endogenous antioxidant are. On the other hand, when there is a decline in the level, there is also a decrease in the activity (Gomes et al., 2012).

Effectiveness of antioxidant systems in offset free radical production reaches saturated conditions in physical activity with a $70 \%$ load of maximal heart rate (Castro et al., 2009), because higher intensity exercise will produce more free radicals(Guzel et al., 2007).

In this study, glutathione peroxides levels is observed to have the tendency to increase in the group given heavy physical training and red-fleshed pitaya extract. This happens as a result of red-fleshed pitaya to have the potential as antioxidant that is able to balance the increase of dree radicals from heavy workouts.

Therefore, glutathione peroxides level is higher in the group that received red dragon fruit extract than the group that did not. The result from this study aligns with the study done by Bing \& Wang (2010) in which stated that Ginkgo Biloba can increase the glutathione peroxidase levels in liver tissue and improve recovering process after a maximum physical activity ( Bing \& Wang, 2010). 
Another research by Suarsana et al. (2013), the application of isoflavone is able to handle SOD decrease and to prevent MDA level from increasing at heart tissues of rats in oxidative stress condition.

\section{Conclusions}

The conclusion of this study is that red-fleshed pitaya has the potential as antioxidant that is able to eliminate oxidative stress due to exhausting physical exercise. Red fleshed pitaya extract as an antioxidant has an effect on increasing glutathione peroxides in rats induced by oxidative stress.

Acknowledgements.We are gratefully to Ministry of Research and Technology and Higher Education Republic of Indonesia under the research grant UNIMED of Year 2018 with the Research Contract Number: 027/UN33.8/ LL /2018.

\section{References}

[1]Abruzzo, P.M., Esposito, F., Marchionni, C., Tullio, S., Belia, S., Fulle S., et al., 2013.

Moderate exercise training inducesros-related adaptations to skeletal muscles. Int. J. Sports

Medicine, vol. 34, pp. 676-687.

[2]Andersson, H., Karlsen, A., Blomhoff, T., Raastad, F., Kadi., 2009. Plasma antioxidant responses and oxidative stress following a soccer game in elite female players. Scand J Med Sci Sports, vol. 10 [3]Azizbeigi, K., Azarbayjani, M.A., Peeri, M., Agha-alinejad, H., Stannard, S., 2013. The effect of progressive resistance training on oxidative stress and antioxidant enzyme activity in erythrocytes in untrained men. International Journal of Sport Nutrition and Exercise Metabolism, vol. 23, pp. 230 238.

[4]Belviranli, M., Gokbel, H., 2006. Acute exercise induced oxidative stress and antioxidant changes. Europe Journal Gen Med. Vol. 3, pp. 126-131.

[5]Bing, Y., and Wang, Z, 2010. Effects of ginkgo biloba extract on free radical metabolism of liver in mice during endurance exercise. Africa Journal Tradit. Complement Altern Med. vol. 7, pp. 291295.

[6]Castro, M.A.C., Neto, F.F.C, Lima, L.M.C., Silva, F.M., Oleiveira, R.J., Zanesco., 2009.

Production of free radical and catalase activity during acute exercise training in young men. Biology of Sport vol. 26. no (2), pp. 113-8.

[7]Castrogiovanni, P., Imbesi, R., 2012. Oxidative stress and skeletal muscle in exercise, Review in Histology and Cell Biology. Italian Journal of Anatomy and Embryology, vol. 117 (2), pp. 107-116. [8]Cooper, C.E., Vollard, N.B., Choueiri, T., Wilson, M.T., 2002. Exercise, free radical wilsonand oxidative stress. Biochem. Soc. Tras vol. 30, pp. 280-285.

[9]Daniel, R.M., Stelian, S., Dragomir, C., 2010. The effect of acute physical exercise on the antioxidant status of the skeletal and cardiac muscle in the wistar rat. Romanian Biotechological Letters, vol. 15 (3): 56-61.

[10]El Abed, K., Masmoudi, L., Koubaa, A, Hakim, A., 2014. Antioxidant in response to anaerobik or aerobik exercise alone or in combination in male judokas. Advances in Life Sciences And Health, vol. 1 (1).

[11]Escribano, B.M., Tunez, I., Requena, F., Rubio, M.D., De Miguel, R., Montilla, P. et al., 2010. Effects of an aerobic training program on oxidative stress biomarkers in bulls. Veterinarni Medicina, vol. 55 , pp. 422-428.

[12]Finaud, J., Lac, G., Filaire, E., 2006. Oxidative stress, relationship with exercise and training. Sport Med, vol. 36(4), pp. 327- 358. 
[13]George, B.O., Osharechiren, O.I., 2009. Oxidative stress and antioxidant status in sports men two hours after strenuous exercise and in sedentary control subjects. African Journal of Biotechnology, vol. 8 (3), pp. 480-483.

[14]Gomes, E.C., Silva, A.N., Oliviera, M.R., 2012. Oxidants, antioxidants, and the beneficial roles of exercise-induced production of reactive species. Oxidative Medicine and Cellular Longevity, vol. 12.

[15]Gomez, Cabrera, M.C., Vina, J., 2009;. Interplay of oxidant and antioxidants during exercise: implication for muscle health. Phys.Sportsmed. vol. 37: 116-123.

[16]Guzel, N.A., Hazard, S., Erbas, D., 2007. Effect of difference resistance exercise protocols on nitric oxide, Lipid peroxidation and creatine kinase activity in sedentary males. Journal of Sports Science andMedicine, vol. 6, pp. 417-22.

[17]Harahap, N.S., Lelo, A., Purba, A., Diningrat, D.S., 2018. Research article combination of weight training with sport massage on 200 meter runners. Journal of Medical Sciences, vol.; 18: 96-102.

[18]Kelsey, W.F., Bloomer, J.R., 2009. Acute exercise and oxidative stress, 30 a year history. Dynamic Medicine, vol. 8 (1) : 1-25.

[19]Kothari, S., Thompson, A., Agarwal, A., Plessis, S.S., 2010. Free Radical: Their beneficial and detrimental effects on sperm function', IndianJournal of Experimental Biology, vol. $48: 425$-35.

[20]Kurkcu, R., Tekin, A., Özda, S., Akçakoyun, F., 2010. The Effects of regular exercıse on oxıdatıve and antioxidative parameters in young wrestlers. African Journal of Pharmacy and Pharmacology, vol. 4 (5), pp. 244-251

[21]Liu, J.F., Chang, W.Y., Chan, K.H., Tsai, W.Y., Lin, C.L., Hsu, M.C., et al. 2005. Blood lipid peroxides and muscle damage increased following intensive resistance training of female weighlifter. Annals of the NewYork Academy of Science, vol. 1042 : 255-261.

[22]Marciniak, A., Brzeszczyńska, J., Gwoździński, K., Jegier, A., 2009. Antioxidant capacity and physical exercise. Journal Biology of Sport, vol. 26 (3):197-213.

[23]Norouziyan, S.,Shemshaki, A., Hanachi, P., 2014. The Effect of Eccentric Exercise on Total AntiOxidant Capacity, Reduced Glutathione and Malondialdehyde Levels in Active Women. Zahedan Journal of Research in Medical Sciences, vol. 16(6): 47-52

[24]Nurul, S.R., Asmah, R., 2014. Variability in nutritional composition and phytochemical properties of red pitaya (Hylocereus polyrhizus) from Malaysia and Australia. International Food Research Journal, vol. 21(4), pp.1689-1697.

[25]Powers, S.K., Jackson, M.J., 2008. Exercise-Induced Oxidative Stress: Cellularm Mechanisms and Impact on Muscle Force Production. PhysiolRev, vol.; 88: 1243-76.

[26]Sani, H.A., Baharoom, A., Ahmad, M.A., Ismail, II., 2009. Effectiveness of hylocereus polyrhizus extract in decreasing serum lipids and liver MDA-TBAR level in hypercholesterolemic rats. Sains Malaysiana, vol. 38: 271-279.

[27]Sahlin, K., Shabalina, I.G., Mattsson, C.M., Linda, B., Fernstrom, M., Rozhdestvenskaya, Z., et al., 2010. Ultraendurance exercise increases the production of reactive oxygen species in isolated mitochondria from human skeletal muscle. Journal Appl Physiol, vol. 108: 780-787.

[28]Suarsana, I.N., Wresdiyati ,T., Suprayogi, A., 2013. Response of oxidative stress and isoflavone treatment on superoxide dismutase enzyme activities and lipid peroxidation in rat's liver. JITV, vol. 18: 146-152.

[29]Urso, M.L., Clarkson, P.M., 2003. Oxidative stress, exercise, and antioxidant supplementation. Toxicology, vol. 189, pp. 41-54.

Valko, M., Leibfritz, D., Moncol, J., Cronin, M.T.D., Mazur, M., Telse,r J., 2007. Free radicals and antioxidant in normal physiological functions and human disease. The International journal of Biochemistry \& Cell Biology, vol. 39:, pp. 44-84. 